\title{
BMJ Open Association between population prevalence of smoking and incidence of meningococcal disease in Norway, Sweden, Denmark and the Netherlands between 1975 and 2009: a population- based time series analysis
}

\author{
Gunnstein Norheim, ${ }^{1,2}$ Manish Sadarangani, ${ }^{1}$ Omar Omar, ${ }^{3}$ Ly-Mee Yu, ${ }^{3}$ \\ Kåre Mølbak, ${ }^{4}$ Michael Howitz, ${ }^{4}$ Per Olcén, ${ }^{5}$ Margaretha Haglund, ${ }^{6}$ \\ Arie van der Ende, ${ }^{7}$ Andrew J Pollard ${ }^{1}$
}

To cite: Norheim G, Sadarangani M, Omar 0 , et al. Association between population prevalence of smoking and incidence of meningococcal disease in Norway, Sweden, Denmark and the Netherlands between 1975 and 2009: a populationbased time series analysis. BMJ Open 2014;4:e003312. doi:10.1136/bmjopen-2013003312

- Prepublication history and additional material for this paper is available online. To view these files please visit the journal online (http://dx.doi.org/10.1136/ bmjopen-2013-003312).

Received 29 May 2013 Revised 21 December 2013 Accepted 10 January 2014

\section{CrossMark}

For numbered affiliations see end of article.

Correspondence to Dr Gunnstein Norheim; gunnstein.norheim@fhi.no

\section{ABSTRACT}

Objective: To investigate the relationship between the prevalence of smoking in the population and incidence of invasive meningococcal disease (IMD) among children under 5 years of age.

Design: Retrospective, longitudinal, observational study. Poisson regression controlled for confounding factors.

Setting: Norway, Sweden, Denmark and the Netherlands between 1975 and 2009.

Population: Total population of approximately 35 million people in these four countries.

Data sources: Data were collected from the Ministries of Health, National Statistics Bureaus and other relevant national institutes.

Results: In Norway, there was a significant positive relationship between the annual prevalence of daily smokers among individuals aged 25-49 years and the incidence of IMD in children under 5 years of age, unadjusted (RR=1.04-1.06, 95\% $\mathrm{Cl} 1.02$ to 1.07, $p<0.001)$ and after adjustment for time of year (quarter), incidence of influenza-like illness and household crowding ( $R R=1.05-1.07,95 \% \mathrm{Cl} 1.03$ to $1.09, p<0.001)$. Depending on age group, the risk of IMD increased by $5.2-6.9 \%$ per $1 \%$ increase in smoking prevalence among individuals aged 2549 years in adjusted analyses. Using limited datasets from the three other countries, unadjusted analysis showed positive associations between IMD in children related to older smokers in Sweden and the Netherlands and negative associations related to younger smokers in Sweden. However, there were no demonstrable associations between incidence of IMD and prevalence of smoking, after adjustment for the same confounding variables.

Conclusions: The reduced incidence of IMD in Norway between 1975 and 2009 may partly be explained by the reduced prevalence of smoking during
Strengths and limitations of this study

- This is the first study to investigate the relationship between smoking and invasive meningococcal disease (IMD) using population-based data.

- We have been able to estimate population attributable risk, and identified risk associated with particular age groups.

- The dataset from Norway enabled robust statistical analysis to assess a potential association between IMD in children $>5$ years of age and daily smoker rate.

- Datasets from Sweden, Denmark and the Netherlands were more limited and did not allow for a comprehensive analysis.

this period. High-quality surveillance data are required to confirm this in other countries. Strong efforts to reduce smoking in the whole population including targeted campaigns to reduce smoking among adults may have a role to play in the prevention of IMD in children.

\section{INTRODUCTION}

Invasive meningococcal disease (IMD) caused by the bacterium Neisseria meningitidis is a major cause of septicaemia and meningitis globally, with a case-fatality rate of $5-10 \%$ and significant sequelae in approximately $20 \%$ of survivors. ${ }^{1-4}$ The incidence of IMD in Europe is $1-27 / 100000 /$ year in 1-4-year-olds, ${ }^{5} 6$ and IMD is the leading infectious cause of early childhood death in the UK. The peak age of disease incidence in Europe is among children 
aged between 6 months and 2 years. $N$. meningitidis, however, is carried asymptomatically in the nasopharynx of approximately $10 \%$ of the population, with highest carriage rates among 15-25-year-olds. ${ }^{7}$ Transmission of bacteria occurs by direct contact with nasal or oral secretions or through inhalation of large droplet nuclei. ${ }^{9}$ Factors which affect transmission, acquisition or invasion of bacteria will, therefore, influence rates of invasive disease.

A number of factors which influence the anatomy or physiology of the nasopharynx have been associated with an increased risk of IMD, including time of year (peaks in winter and spring), special climatic conditions (eg, dry season and dust storm), concurrent respiratory tract infection and smoking. ${ }^{10}$ In addition, active smoking ${ }^{8}$ 11-14 and exposure to second-hand smoke ${ }^{8}$ 15-17 have been associated with an increased risk of carriage of N. meningitidis. Multivariate analyses from case-control studies suggested an association between exposure to tobacco smoke and the risk of meningococcal disease and/or carriage, ${ }^{18-23}$ with ORs of up to 9.1 in children under 6 years of age. ${ }^{19}$ In one study, $37 \%$ of IMD in children was attributed to maternal smoking, ${ }^{22}$ and a doseresponse effect between smoking and IMD has also been suggested. ${ }^{22}$

The overall prevalence of smoking has declined significantly during the past 30 years in industrialised countries. $^{24}$ The introduction of smoking bans in public places in a number of countries worldwide has demonstrated that there is a political will to sustain this trend. During this time, Norway and the Netherlands experienced hyperendemic IMD, but there has been a marked reduction in incidence in both countries during the last decade. Sweden and Denmark have had a relatively low incidence of IMD throughout this period. All four countries introduced smoking bans between 1988 and 2007. While there are a large number of case-control studies identifying smoking as a risk factor for IMD, there are limited data to investigate if there is any relationship at a population level, and to, therefore, establish if interventions to reduce smoking would have any impact on the incidence of IMD.

\section{METHODS}

\section{Selection of confounding variables}

The primary study objective was to assess the relationship between the prevalence of smoking and incidence of IMD in children $<5$ years between 1975 and 2009. The rationale behind selecting children $<5$ years was that the highest incidence of IMD in Europe occurs among this age group. ${ }^{5}$ Potential confounding variables to be included in the statistical analysis were initially identified by PubMed searches, references from relevant articles and the reports of health agencies of relevant countries. PubMed search terms were "neisseria", "meningitidis", "meningococcal", "meningitis", "septicaemia”, "smoking”, "tobacco”, “exposure", "environmental", "risk", "association”, "multivariate”, "odds ratio" and "protection". A number of factors associated with altered risk of IMD were identified. Those considered for inclusion were independently associated with meningococcal disease and/or carriage in a multivariate analysis with an OR of $\geq 2$ or $\leq 0.5$ and demonstrated biological plausibility ${ }^{18-2325-29}$ (see online supplementary table S1). Of these, data were available from all countries for rates of influenza-like illness (ILI) and levels of household crowding, which were subsequently included in the analyses. The only protective risk factors identified according to these criteria in the case-control studies were meningococcal vaccination ${ }^{29}$ and attendance at religious ceremonies, ${ }^{29}$ of which the latter was not adjusted for due to the age group in consideration. Meningococcal vaccination was only relevant to the Netherlands due to implementation of a serogroup $\mathrm{C}$ meningococcal vaccine in 2001, and this was taken into account. In Norway, there is no routine immunisation against meningococcal disease, but a clinical trial with a serogroup B vaccine was performed with 180000 Norwegian teenagers in 1988-1991. However, the vaccinated individuals were 14-16 years of age at the time of vaccination. ${ }^{30}$ Since this age group does not frequently mix with children of $<5$ years of age ${ }^{31}$ and there is no apparent effect on carriage, previous meningococcal vaccination was, therefore, not taken into account.

\section{Definitions}

The incidence of IMD was based on the number of laboratory-confirmed cases per year per 100000 children in the population prior to their fifth birthday. Laboratory confirmation was based on a positive bacterial culture in blood or cerebrospinal fluid, with the additional use of PCR from 1999 (Norway), 2002 (Sweden), 2003 (the Netherlands) or 2005 (Denmark). Annual smoking prevalence was measured using the percentage of the population who were regular daily smokers, categorised by 5-10-year-age bands and gender wherever these data were available. An overcrowded household was defined as a household containing more than one person per room (excluding kitchen and bathroom for all countries and also excluding living rooms in Sweden). In Norway and Denmark, a single person living in one room was also defined as an overcrowded household. In Norway and the Netherlands, weekly rates of ILI were measured per 100000 population based on the data from sentinel surveillance centres. In Sweden and Denmark, the proportion of all consultations which were for ILI among the surveillance centres was used. For Sweden, laboratory data on the number of confirmed influenza isolates were used as these data were available from 1994, whereas data on consultation rates were only available from 2001. Comparison of data from 2001 to 2009 showed good correlation between the two datasets $\left(\mathrm{R}^{2}=0.73\right.$ by linear regression analysis, data from $\mathrm{n}=246$ weeks, $\mathrm{p}<0.001$, data not shown), and relying on laboratory-confirmed cases of influenza justified the use of the laboratory-based data in our statistical model. Additional country-specific issues are described below. 


\section{Data sources}

Norway, Sweden, Denmark and the Netherlands were selected for study due to the high quality of surveillance for IMD and smoking prevalence over a long period of time. The smoking prevalence data were obtained by surveys among representative selections of the population in the four different target countries. The study countries are also comparable in terms of socioeconomic equality, as measured by income distribution (Gini-coefficient $<30$ for all; OECD). For each dataset in each country, the public organisation responsible for surveillance was asked to provide the most detailed data available, some of which were already in the public domain (eg, published on relevant organisation website). In some cases, additional data were obtained from independent sources to enable robust analyses (table 1).

The Netherlands introduced routine infant immunisation with a meningococcal serogroup $\mathrm{C}$ conjugate vaccine in September 2002, so this analysis only included cases of non-serogroup C disease. Surveillance methods for estimation of ILI incidence in Norway did change during the study period, and have been described previously. ${ }^{33}$ Briefly, between 1975 and 1998 all general practices and outpatient emergency clinics were obliged to report episodes of ILI. Rates of ILI were calculated as a proportion of the total population, without adjusting for the reporting coverage. From 1998, there were 201 sentinel reporting units located throughout Norway used to calculate incidence rates.

\section{Statistical methods}

Poisson regression models were used to estimate incidence rate ratios, with and without adjustment for time (annually for Denmark, Sweden and the Netherlands, or quarterly for Norway), ILI and household crowding using Stata V.11 (StataCorp, College Station, Texas, USA). These estimate the average relative change in IMD incidence per unit increase in smoking prevalence. Each analysis was performed over the longest time period for which all relevant data were available, so in some cases, adjusted analyses covered shorter durations than unadjusted analyses. Separate models were fitted for each country and for every age-specific and genderspecific group of smokers where data were available. The analyses were repeated using the Generalised Estimating Equation (GEE) method to account for the autocorrelation structure of the data. The results were similar to those obtained from the Poisson regression model, and therefore are not reported here. The methodology for calculating the population-attributable risk was performed as previously described. ${ }^{34}$

For Norway, quarterly data were used for incidence of IMD and an assumption was made that smoking prevalence and crowding rates were constant for each quarter of a year. In addition, ILI data for Norway were transformed to allow for the different reporting systems before and after 1998. Three low-incidence influenza seasons with the old reporting system (pre-1998) and three with the new system (post-1998) were selected, and the average number of cases reported per season in the pre-1998 seasons was divided by the average number of cases for the three post-1998 seasons. Every data point was then multiplied by this factor to calculate a standardised ILI rate which could be used throughout the study period.

Imputation was performed when ILI and crowding data were not available. For simplification of analysis, missing values were assumed to be missing at random. In order to avoid a loss in efficiency missing values for ILI were imputed using multiple imputation by chained equations. $^{35}$ Ten imputed datasets were created by replacing missing values with simulated values from a set of imputation models built from all potential prognostic variables (smoking prevalence, household crowding and ILI rate) and the outcome variable (incidence of IMD). Poisson regression analysis was performed on each imputed dataset and the imputation-specific coefficients were combined using Rubin's rules. ${ }^{36}$ 'Year' and 'Quarter' terms were included in the model as linear terms to take into account linear trends over time.

\section{RESULTS}

\section{Data availability}

Annual incidence of IMD in children under 5 years of age and a measure of the yearly prevalence of smoking in each country were available for all countries for most of the study period, with the most complete datasets obtained from Norway and the Netherlands (table 1). Data for overcrowding were the most difficult to obtain due to the infrequent and inconsistent methods used for its estimation. All data were included in the analyses, except crowding data from the Netherlands due to the lack of sufficient data points.

\section{Norway}

The incidence of IMD in children under 5 years of age in Norway increased from 1977 to 1983-1984 with an incidence of 25-45/100 000/year, and then declined steadily to $<5 / 100000 /$ year after 2004 (figure 1 ). The prevalence of daily smokers decreased over the same time period in all age groups, from $25-49 \%$ to $13-26 \%$, depending on the age group (figure 1). There was a significant positive association between incidence of IMD and prevalence of smoking in the unadjusted analysis, with an increase of $2.7-5.7 \%$ in IMD incidence per $1 \%$ rise in prevalence of daily smokers (table 2). The population attributable risk per cent ranged from $1 \%$ to $1.9 \%$ for the age groups with a significant association in the unadjusted analysis, totalling $11.4 \%$ for these seven groups (table 2).

During the study period, there was a steady decline in household crowding, from $16 \%$ of the population living in a crowded household in 1980 down to $6 \%$ in 2007 (figure 2). In contrast, the rate of ILI remained 
Table 1 Data sources and availability

\begin{tabular}{|c|c|c|c|c|c|}
\hline \multirow[b]{2}{*}{ Data item } & \multirow[b]{2}{*}{ Target dataset } & \multicolumn{4}{|l|}{ Country } \\
\hline & & Norway & Sweden & Denmark & The Netherlands \\
\hline $\begin{array}{l}\text { Incidence of invasive } \\
\text { meningococcal } \\
\text { disease }\end{array}$ & $\begin{array}{l}\text { Annual incidence in children } \\
<5 \text { years of age }\end{array}$ & $\begin{array}{l}\text { NIPH } \\
\text { Quarterly incidence } \\
<5 \text { years, } \\
1977-2009\end{array}$ & $\begin{array}{l}\text { National reference Laboratory } \\
\text { for Pathogenic Neisseria } \\
\text { Annual incidence all ages, } \\
\text { 1975-2009 (<5 years from } \\
\text { 1997) }\end{array}$ & $\begin{array}{l}\text { Department of } \\
\text { Epidemiology, Statens } \\
\text { Serum Institut } \\
\text { Annual incidence } \\
<5 \text { years, 1975-2007 }\end{array}$ & $\begin{array}{l}\text { The Netherlands } \\
\text { Reference Laboratory for } \\
\text { Bacterial Meningitis } \\
\text { Annual incidence }<5 \text { years, } \\
\text { 1980-2009 }\end{array}$ \\
\hline $\begin{array}{l}\text { Prevalence of } \\
\text { smoking }^{*}\end{array}$ & $\begin{array}{l}\text { Annual percentage of population } \\
\text { who are daily smokers (ideally } \\
\text { age-specific and gender-specific) }\end{array}$ & $\begin{array}{l}\text { Norwegian } \\
\text { Directorate for } \\
\text { Health } \\
\text { Annual } \\
\text { age-specific data, } \\
\text { 1975-2009 }\end{array}$ & $\begin{array}{l}\text { National Institute of Public } \\
\text { Health } \\
\text { Annual age-specific and } \\
\text { gender-specific data, 1980- } \\
2007\end{array}$ & $\begin{array}{l}\text { OECD and ISS } \\
\text { Annual gender-specific } \\
\text { data, 1975-2008 }\end{array}$ & $\begin{array}{l}\text { OECD and STIVORO } \\
\text { Annual gender-specific } \\
\text { data, 1975-2009 }\end{array}$ \\
\hline Rate of ILI & $\begin{array}{l}\text { Weekly consultation rate among } \\
\text { sentinel centres for ILI during } \\
\text { influenza season (weeks 1-20 } \\
\text { and 40-52) }\end{array}$ & $\begin{array}{l}\text { NIPH } \\
\text { Weekly rate, } \\
\text { 1975-2009 }\end{array}$ & $\begin{array}{l}\text { Department of Epidemiology, } \\
\text { Swedish Institute for } \\
\text { Communicable Disease } \\
\text { Control† } \\
\text { Weekly rate, 1994-2009 }\end{array}$ & $\begin{array}{l}\text { Statens Serum Institut } \\
\text { Weekly rate, 1994-2009 }\end{array}$ & $\begin{array}{l}\text { NIVEL } \\
\text { Weekly rate, 1975-2009 }\end{array}$ \\
\hline Overcrowding & $\begin{array}{l}\text { Annual percentage of population } \\
\text { living in a crowded household }\end{array}$ & $\begin{array}{l}\text { Statistics Norway } \\
\text { Data every } \\
2-4 \text { years, } \\
1980-2007\end{array}$ & $\begin{array}{l}\text { Statistics Sweden } \\
\text { Data every } 2 \text { years, 1980-2007 }\end{array}$ & $\begin{array}{l}\text { Statbank Denmark, } \\
\text { Statistics Denmark } \\
\text { Annual data, 1981-2009 }\end{array}$ & $\begin{array}{l}\text { Central Bureau of Statistics } \\
\text { Data every 3-5 years, } \\
\text { 1981-2009 }\end{array}$ \\
\hline
\end{tabular}

*Based on survey data on self-reported status of smoking.

†Based on laboratory-confirmed cases of ILI rather than consultation rate due to greater availability of data.

ISS, International Smoking Statistics ${ }^{32}$; ILI, influenza-like illness; NIPH, Norwegian Institute of Public Health, Oslo, Norway; NIVEL, The Netherlands Institute for Health Services Research,

Utrecht, The Netherlands (www.nivel.nl); OECD, Organisation for Economic Co-operation and Development (www.oecd.org); STIVORO, Stichting Volksgezondheid en Roken, Den Haag, The Netherlands (http://www.stivoro.nl). 

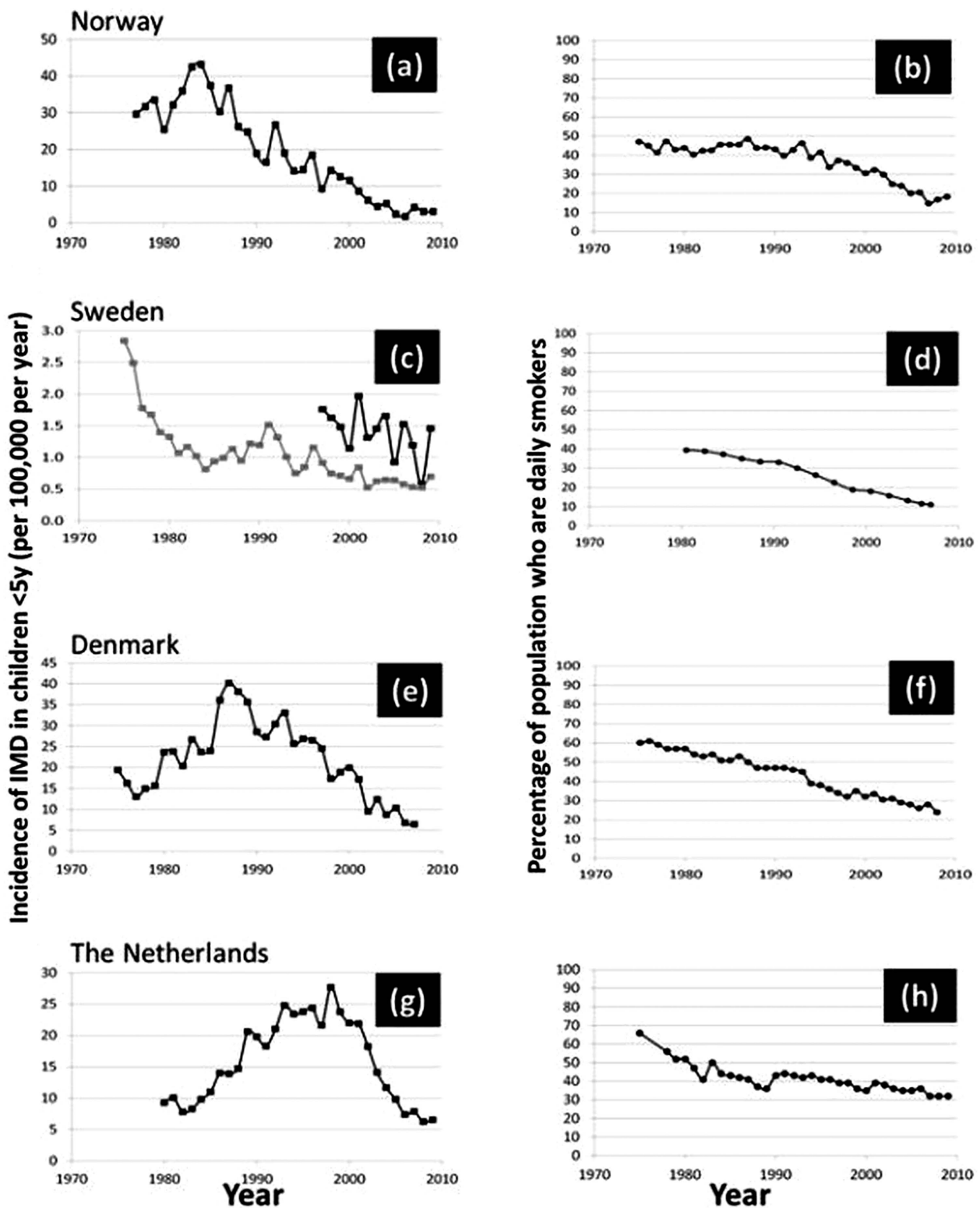

Figure 1 Trends of incidence of invasive meningococcal disease in children $<5$ years of age and prevalence of daily smokers in Norway (A and B), Sweden (C and D), Denmark (E and F) and the Netherlands ( $G$ and H) between 1975 and 2009 . Incidence of invasive meningococcal disease (IMD) in children $<5$ years of age is shown in $(A),(C),(E)$ and $(G)$. Percentage of population who are daily smokers is in $(B),(D),(F)$ and $(H)$. For Sweden, additional data illustrating the incidence of IMD in all age groups is depicted in the grey line, due to the limited availability of data for children $<5$ years of age. For the Netherlands, data for non-serogroup C disease only are shown. For Norway, smoking data for the 30-34 years of age group are shown. For Sweden, smoking data for the 35-44 years male group are shown. For Denmark and the Netherlands, data for males only are shown. In all countries age groups and genders not shown followed similar trends. The incidence of IMD has decreased in children in all four countries since the 1990s, and in Norway throughout the study period. The prevalence of smoking has decreased in all four countries during the study period.

relatively constant, other than the usual seasonal variation. The apparent abrupt change in 1998 coincided with a change in the method of data collection, which was corrected for in the analysis. The pre-1998 system ended in week 20 of 1998, whereas the post-1998 system started in week 40 of 1998. The distribution of the covariates is shown in online supplementary table S2. After adjusting for ILI and household crowding, a positive association remained between incidence of IMD in children < 5 years and prevalence of smoking in the population for all age groups between 25 and 59 years, except the 50-54 years group (table 3 ). There was an increase of $2.5-6.9 \%$ in IMD incidence per $1 \%$ rise in prevalence of daily smokers.

\section{Sweden}

The incidence of IMD in children $<5$ years was only available from 1997 onwards, limiting analysis that was 
Table 2 Unadjusted age-specific and sex-specific relative risk of IMD in children aged $<5$ years according to annual percentage of daily smokers in different genders age groups in Norway, Sweden, Denmark and the Netherlands between 1975 and 2009

\begin{tabular}{|c|c|c|c|c|c|}
\hline Country and years & Age group (years) & Gender & $\begin{array}{l}\text { Relative risk of IMD } \\
\text { associated with a } 1 \% \\
\text { increase in prevalence } \\
\text { of smoking }(95 \% \mathrm{Cl})\end{array}$ & p Value & $\begin{array}{l}\text { Population } \\
\text { attributable risk (\%) }\end{array}$ \\
\hline Norway & $16-19$ & $\mathrm{M}, \mathrm{F}$ & $0.99(0.98$ to 1.00$)$ & 0.155 & -0.2 \\
\hline \multirow[t]{9}{*}{ 1977-2009 } & $20-24$ & $\mathrm{M}, \mathrm{F}$ & 1.01 (1.00 to 1.03$)$ & 0.185 & 0.3 \\
\hline & $25-29$ & $\mathrm{M}, \mathrm{F}$ & $1.04(1.02$ to 1.06$)$ & $<0.001^{*}$ & 1.4 \\
\hline & $30-34$ & $\mathrm{M}, \mathrm{F}$ & 1.05 (1.04 to 1.06$)$ & $<0.001^{*}$ & 1.8 \\
\hline & $35-39$ & $\mathrm{M}, \mathrm{F}$ & 1.05 (1.03 to 1.06$)$ & $<0.001^{\star}$ & 1.9 \\
\hline & $40-44$ & $\mathrm{M}, \mathrm{F}$ & 1.06 (1.04 to 1.07$)$ & $<0.001^{*}$ & 2.1 \\
\hline & $45-49$ & $\mathrm{M}, \mathrm{F}$ & 1.06 (1.04 to 1.07$)$ & $<0.001^{*}$ & 2.2 \\
\hline & $50-54$ & $\mathrm{M}, \mathrm{F}$ & 1.01 (1.00 to 1.03$)$ & 0.123 & 0.3 \\
\hline & $55-59$ & $\mathrm{M}, \mathrm{F}$ & 1.03 (1.01 to 1.04$)$ & $<0.001^{\star}$ & 1 \\
\hline & $\geq 60$ & $\mathrm{M}, \mathrm{F}$ & 1.04 (1.02 to 1.06$)$ & $<0.001^{*}$ & 1 \\
\hline Sweden & $16-24$ & M & 0.95 (0.93 to 0.98$)$ & $<0.001^{*}$ & -0.8 \\
\hline \multirow[t]{9}{*}{ 1993-2007 } & & $\mathrm{F}$ & $0.96(0.94$ to 0.98$)$ & $<0.001^{*}$ & -0.9 \\
\hline & $25-34$ & M & 0.98 (0.96 to 0.99$)$ & $0.007^{\star}$ & -0.5 \\
\hline & & $\mathrm{F}$ & $1.02(1.00$ to 1.04$)$ & 0.119 & 0.5 \\
\hline & $35-44$ & M & $1.07(1.04$ to 1.10$)$ & $<0.001^{*}$ & 1.8 \\
\hline & & $\mathrm{F}$ & $1.05(1.03$ to 1.07$)$ & $<0.001^{\star}$ & 1.4 \\
\hline & $45-54$ & M & $1.01(1.00$ to 1.04$)$ & 0.214 & 0.3 \\
\hline & & $\mathrm{F}$ & 1.04 (1.03 to 1.06$)$ & $<0.001^{*}$ & 1.1 \\
\hline & $55-64$ & M & 0.94 (0.92 to 0.97$)$ & $<0.001^{*}$ & -1.6 \\
\hline & & $\mathrm{F}$ & $0.99(0.97$ to 1.01$)$ & 0.434 & -0.2 \\
\hline Denmark & $\geq 15$ & M & $1.00(0.95$ to 1.06$)$ & 0.947 & 0 \\
\hline 1975-2007 & & $\mathrm{F}$ & 0.94 (0.88 to 1.02$)$ & 0.135 & -1.7 \\
\hline The Netherlands & $15-19$ & $\mathrm{M}, \mathrm{F}$ & $1.01(0.96$ to 1.06$)$ & 0.797 & 0.2 \\
\hline \multirow[t]{2}{*}{ 1980-2009† } & $20-34$ & $M, F$ & 0.99 (0.92 to 1.07$)$ & 0.860 & -0.4 \\
\hline & $35-49$ & $\mathrm{M}, \mathrm{F}$ & $1.13(1.08$ to 1.19$)$ & $<0.001^{*}$ & 4.5 \\
\hline
\end{tabular}

possible within the target age group. Nevertheless, there was a decrease in the incidence of IMD in this group between 1997 and 2009 from 1.76 to 1.46/100 000/year.

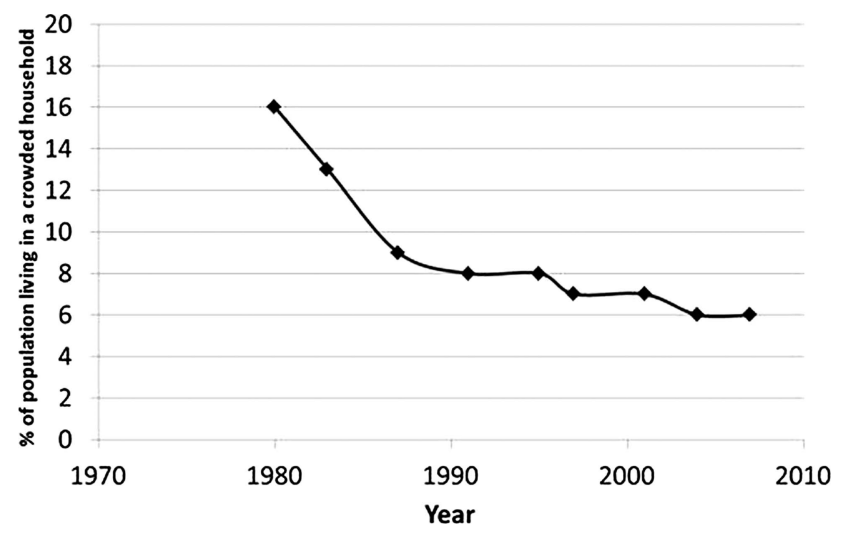

Figure 2 Percentage of the population living in a crowded household during 1980-2007 in Norway. Data retrieved from Statistics Norway (http://www.ssb.no).
A similar trend was apparent during the same time period for smoking prevalence in all age and gender groups (figure 1). The relative decrease in smoking prevalence was between $25.7 \%$ (in 16-24-year-old men) and $47 \%$ (in 35-44-year-old women). In all age and gender groups, these trends in smoking prevalence were occurring from 1980. In the unadjusted analysis, there was an increased risk of IMD in children $<5$ years related to smokers aged $35-54$ years, whereas a reduced risk was seen related to smokers aged 16-34 years (table 2). Adjustment for household crowding and ILI could only be performed on data between 1997 and 2009, and there was no significant relationship between smoking and IMD in this limited analysis. Data on overall incidence of IMD were, however, available from 1980, and since there was a high correlation between the overall IMD incidence (all ages) and incidence of IMD in children $<5$ years of age for the years when both were measured, an additional analysis was performed using these data. After adjustment for household crowding, there 
Table 3 Adjusted relative risk of invasive meningococcal disease in children aged $<5$ years according to annual percentage of daily smokers in different age groups in Norway between 1977 and 2007, after adjustment for quarter, influenza-like illness and household crowding

\begin{tabular}{llr}
\hline & $\begin{array}{l}\text { Relative risk of IMD } \\
\text { associated with a 1\% increase } \\
\text { in prevalence of smoking } \\
\text { (years) }\end{array}$ & $\begin{array}{l}\text { (95\% Cl) } \\
\text { p Value }\end{array}$ \\
\hline $16-19$ & $1.00(0.98$ to 1.01$)$ & 0.582 \\
$20-24$ & $1.01(0.99$ to 1.03$)$ & 0.301 \\
$25-29$ & $1.05(1.03$ to 1.07$)$ & $<0.001^{*}$ \\
$30-34$ & $1.05(1.04$ to 1.07$)$ & $<0.001^{*}$ \\
$35-39$ & $1.06(1.05$ to 1.08$)$ & $<0.001^{*}$ \\
$40-44$ & $1.07(1.05$ to 1.08$)$ & $<0.001^{*}$ \\
$45-49$ & $1.07(1.05$ to 1.09$)$ & $0.001^{*}$ \\
$50-54$ & $1.01(1.00$ to 1.03$)$ & $<0.001^{*}$ \\
$55-59$ & $1.03(1.01$ to 1.04$)$ & $0.002^{*}$ \\
$\geq 60$ & $1.04(1.01$ to 1.06$)$ &
\end{tabular}

${ }^{*}$ Statistically significant $(p<0.05)$ association between prevalence of smoking and incidence of IMD in children $<5$ years of age. IMD, invasive meningococcal disease.

was a significant association between overall incidence of IMD and prevalence of smoking in all groups, except smoking prevalence in 55-64-year-old women (table 4). There was no clear-cut relationship, since some smoking age groups appeared to confer an increased risk of IMD and others a reduced risk.

\section{Denmark and the Netherlands}

Similar patterns of IMD incidence were observed in both of these countries, with initial increase in incidences

Table 4 Adjusted relative risk of invasive meningococcal disease in children and adults (all ages included) according to annual percentage of daily smokers in different genders and age groups in Sweden between 1980 and 2007, after adjustment for year and household crowding

\begin{tabular}{lllr}
\hline $\begin{array}{l}\text { Age } \\
\text { group } \\
\text { (years) }\end{array}$ & Gender & $\begin{array}{l}\text { Relative risk of IMD } \\
\text { associated with a 1\% } \\
\text { increase in prevalence }\end{array}$ & \\
\hline $16-24$ & of smoking (95\% Cl) & p Value \\
& F & $0.93(0.90$ to 0.95$)$ & $<0.001^{*}$ \\
$25-34$ & M & $0.94(0.91$ to 0.96$)$ & $<0.001^{*}$ \\
& F & $1.05(1.01$ to 1.08$)$ & $0.002^{*}$ \\
$35-44$ & M & $1.11(1.07$ to 1.15$)$ & $<0.005^{*}$ \\
& F & $1.07(1.04$ to 1.10$)$ & $<0.001^{*}$ \\
$45-54$ & M & $1.04(1.00$ to 1.08$)$ & $0.041^{*}$ \\
& F & $1.06(1.04$ to 1.09$)$ & $<0.001^{*}$ \\
$55-64$ & M & $0.95(0.93$ to 0.98$)$ & $0.004^{*}$ \\
& F & $1.01(0.98$ to 1.04$)$ & 0.376 \\
\hline
\end{tabular}

* Statistically significant $(p<0.05)$ association between prevalence of smoking and incidence of IMD

IMD, invasive meningococcal disease; $F$, female; $M$, male. before a subsequent decrease. The incidence peaks were in 1987 in Denmark and 1998 in the Netherlands. Both countries experienced a steady decrease in prevalence of smoking between 1975 and 2008-2009 (figure 1). There were no significant associations between incidence of IMD and prevalence of smoking in the unadjusted analysis in Denmark (table 2), although age-specific data on smoking prevalence were not available. In the Netherlands, unadjusted analyses showed a significant association between IMD in children $<5$ years of age and daily smoker rate among individuals aged 35-49 years of age, but were not significant after adjustment for ILI and household crowding. Adjustment for overcrowding could not be performed with the dataset from the Netherlands due to lack of sufficient data points.

\section{DISCUSSION}

\section{Main findings}

This study provides further evidence that exposure to tobacco smoke is an independent risk factor which increases the risk of IMD. Of the four countries studied, the most complete dataset for IMD, smoking, ILI and household crowding was obtained from Norway. Over a 34-year period, a 5.2-6.9\% increase in IMD in children under 5 years of age was observed for every $1 \%$ rise in prevalence of smoking in adults aged between 25 and 49 years. Taken together with previous case-control studies showing smoking as a risk factor for contracting IMD, the reduction in smoking prevalence that has occurred in Norway during this period is likely to have made a significant contribution to the concurrent reduction in incidence of IMD. The proportion of IMD cases under 5 years of age in the total population that could be attributed to active smoking in Norway was found to be $11.4 \%$, which is far lower than that estimated in other studies for young children. ${ }^{22} 37$ The lack of demonstrable associations between incidence of IMD and prevalence of smoking, after adjustment for the same confounding variables, in Denmark, Sweden and the Netherlands may in part be ascribed to the limited datasets available. The absence of statistically significant associations is hence difficult to interpret, although unadjusted analysis showed positive associations between IMD in children related to older smokers in Sweden and the Netherlands. In contrast, negative associations were found related to younger smokers in Sweden. These mixed patterns of associations may indicate that not all biologically relevant confounding factors were accounted for.

\section{Strengths and limitations}

This study has allowed exploration of the relationship between IMD and exposure to tobacco smoke using an approach that has not previously been considered. The study provides a long-term, population-based observational study over a 30 -year time period that we believe is valuable to provide evidence of the longitudinal 
association between smoking and IMD, while previous evidence was primarily based on case-control studies and biological model studies. Furthermore, we have provided estimates of population-attributable risk, and identified risk associated with particular age groups. The study highlights the relevance of long-term monitoring of infectious disease risk factors and standardised reporting formats between countries. The existence of surveillance systems in some European countries with databases which, to a large extent, could be interrogated historically back to the 1970s has allowed observation of trends not only for incidence of IMD and prevalence of smoking over 34 years, but also correction for the major confounding variables of household crowding and ILI. The Norwegian dataset was reasonably complete, allowing for a comprehensive analysis to assess a potential association between IMD in children $<5$ years of age and daily smoker rate, whereas the available datasets for Sweden, Denmark and the Netherlands were more limited. For Sweden, there were no data available on IMD incidence in children $<5$ years of age for the period prior to 1997 , and no data on ILI rates prior to 1994. The change in IMD incidence in children $<5$ years of age during the relatively short period for which a full dataset was available was also relatively minor. Hence, the apparent lack of association may also have been impacted by the limitations in data availability. This was also the case for the data from the Netherlands and Denmark, where data were not as comprehensive as from Norway where the completeness of the dataset was high apart from data on crowding. Specifically, for the Netherlands, there was insufficient information to include an adjustment for household crowding, and there was a lack of age-specific data on smoking prior to 1995. For Denmark, there was insufficient frequency of age-specific data on smoking, and no data on ILI rates prior to 1994. The analyses performed here within should be repeated at a later time point, when longer time series of full datasets are available from Denmark, Sweden and the Netherlands. Analyses were performed over the longest possible period with consistent data collection methods. In Norway, there was a change in ascertainment of ILI during the study period, and this was corrected for in the analysis in consultation with those responsible for collecting the data. There was unfortunately no time period in which both collection methods were used, hence in order to ensure one full time series dataset, we bridged the datasets by a transformation procedure as described above. We cannot rule out that this may have confounded the assessment of the association between the variables.

The accuracy of smoking prevalence data obtained by self-report surveys has been discussed in the scientific literature, ${ }^{38}$ as there may be inaccuracy due to misreporting of smoking status and the failure to include non-cigarette tobacco smoking. ${ }^{38}$ Using the measurement of the nicotine-derived metabolite cotinine in biological fluids as a marker of tobacco exposure in individuals, studies have found that the self-reported status of smoking may underestimate the true tobacco exposure. In this study, we could not determine any variability in exposure measurement error over time. However, it is often reported that the level of inaccuracy is low. ${ }^{38}$ In the current study, the self-reported survey method was used for all countries over the whole time period to measure the daily smoker prevalence, and the association studies performed were hence not likely to be severely affected by this.

The major limitation of the study was the availability of data for ILI and household crowding in terms of duration and frequency of data collection, requiring some imputation. Differences found between countries may simply be a reflection of data availability, or may represent true differences. As with any analysis of association between two variables over such a long time period, there may be a number of confounding variables for which it was not possible to completely adjust. Specific to meningococcal disease, most previously described risk factors relate to closeness of contact or preceding illness. Although adjusting based on ILI and household crowding would account for many related factors, there may be additional confounders which we were not able to include in the analysis, such as exposure to a person from jail, recent analgesia use and attendance on religious ceremonies. ${ }^{21} \quad 23 \quad 29$ Additional factors such as differential effects of the pathogens responsible for ILI ${ }^{33}$ or degree of household crowding were not considered due to lack of data. During the study period, a number of other changes in society may have occurred, including changes in diet and exercise habits, socialisation behaviour and antimicrobial usage, which may influence the rate of IMD. These changes are, however, more difficult to quantify due to lack of timeseries data and were therefore not included in our statistical models. An association between meteorological variables (ie, temperature and humidity) and the prevalence of acute respiratory tract infections (ARIs) has been documented, ${ }^{39}$ and some studies suggest an association between ARIs and meningococcal disease ${ }^{40-42}$ Changes in meteorological variables (eg, average winter temperature) may affect the invasion of meningococci across the epithelial barrier and hence the incidence of meningococcal disease, and should be further studied. In this study, we have included ILI as a confounding factor; however, other causes of ARIs were not included due to a lack of timeseries data. Over time, the incidence of meningococcal disease does naturally fluctuate within a population due to multiple possible mechanisms, but consideration of a long period in this study makes the results less likely to be affected by such fluctuations. Although it is not possible to rule out other factors directly or indirectly being responsible for the association found in this study (eg, meteorological variables), concurrence with multiple case-control studies which include extensive multivariate analyses adds to the evidence base showing an association between IMD and smoking. Since these were population level data and we were able to adjust for gender and age at population 
level, it is, however, not possible to draw conclusions about the effect at an individual level (ecological fallacy) as the danger of using ecological studies to draw biological inference in public health has been well documented due to the potential disconnection between the level of inference and the level of analysis. ${ }^{43}$

In this study, we did not stratify on N. meningitidis genotypes due to the lack of consistent genotyping data over the whole study period. This may affect short-term fluctuations in incidence since the initiation of an epidemic is thought to occur by the introduction of a hypervirulent clone into a susceptible population, ${ }^{44}$ whereas the waning of an meningococcal epidemic over years following a peak is hypothesised to be due to an increasing immunity against the epidemic clone in the general population. ${ }^{45}$ The hyperinvasive meningococcal strain types that caused the epidemic waves in Norway (ST-32 clonal complex) and the Netherlands (ST-41/44 clonal complex) seem to have minimal lifespans of 36 and 26 years, respectively. ${ }^{45}$ It could be hypothesised that when a sufficient proportion of an immunologically susceptible population are daily smokers, the spread of a newly introduced virulent strain is far more successful. This is supported by the finding that elevated carriage levels being more likely to occur in a population with a high rate of daily smokers. One moderating factor is that the case to carrier rate varies between the different hyperinvasive strain types. Ultimately, there may also be unknown factors needed to trigger an epidemic that our analysis did not account for.

\section{Comparison with other studies}

Although there are a number of case-control studies which have shown exposure to tobacco smoke to be a significant risk factor for meningococcal disease and carriage, this is the first study to demonstrate the association at a population level, which therefore has major public health implications. A large number of previous casecontrol studies have found exposure to tobacco smoke to be a major risk factor for carriage of $N$. meningitidis as well as invasive disease. Studies investigating the association of smoking with IMD have been performed throughout Europe, North America and Australasia, and generally considered exposure to tobacco smoke in the 2-4 weeks prior to disease. ${ }^{18-23}{ }^{25-29}$ The children who had a parent or carer who smoked, particularly if the smoker was the mother, were most strongly associated with IMD. Although some clear trends are apparent from these studies, there are several limitations. First, different measures have been used to estimate exposure to tobacco smoke. If tobacco smoke increases the risk of IMD by promoting meningococcal carriage in teenagers and young adults, then the number of smoker contacts would be the most important factor. If, however, there is a direct effect of tobacco smoke increasing the risk of bacterial invasion, then overall exposure to smoke should be considered. Both mechanisms may play a role, and there is undoubtedly a confounding effect between these two factors. We have used prevalence of daily smokers as a measure of exposure to tobacco smoke, which primarily reflects number of smoker contacts, and also overall exposure to smoke. In addition, the age groups considered in past studies are not consistent, with tobacco smoke appearing to be a risk factor for IMD primarily in younger children. A further problem is that many studies suggest that an association exists, but the ORs/RRs do not reach significance due to the small number of IMD cases and relatively low proportion of smokers, and many studies do not include a multivariate analysis. In those studies where a multivariate analysis has been carried out, different confounding factors are included in the models, making it difficult to compare. A recent meta-analysis found that second-hand exposure to tobacco smoke was associated with a significantly increased risk of IMD with an OR of 2.02 (95\% CI 1.52 to 2.69$).{ }^{46}$ In the three studies specifically addressing pre-school children ( $\leq 6$ years), the association was stronger, but non-significant $(\mathrm{OR}=3.04,95 \%$ CI 0.89 to 10.47$)$, most likely due to inadequate power even with the combined analysis. The population-level approach used in our study complements previous casecontrol studies and supports the same conclusion that exposure to tobacco smoke does adversely influence the risk of IMD.

Humans are the sole reservoir for $N$. meningitidis, with asymptomatic carriage of the organism occurring in the nasopharynx. In a small number of individuals, bacteria invade into the bloodstream and thereafter the central nervous system. The risk for a young child of developing IMD is, therefore, dependent on factors which affect acquisition of the organism (eg, contact patterns, carriage rates of contacts and environmental factors, including exposure to tobacco smoke $\left.{ }^{18} 1922\right)$ combined with factors which influence invasion (eg, strain virulence, host immunity and integrity of the nasopharyngeal mucosal surface). The age relationship between primary and secondary cases of meningococcal disease ${ }^{47}$ closely resembled the patterns found in studies of physical contacts. ${ }^{31}$ Young children are mostly in close contact with other children of the same age and adults aged 2044 years, presumably representing the demographics of parents and carers. ${ }^{31} 48$ Anything which significantly affects meningococcal carriage in this age group would, therefore, have a high impact on transmission, and therefore incidence of invasive disease, in young children. Carriage rates of $N$. meningitidis were elevated among smokers compared with non-smokers in a number of studies from Europe, the USA, New Zealand and Burkina Faso, with rates usually 2-3 times higher in smokers. ${ }^{811-174950}$ Tobacco smoke also affects integrity of the nasopharyngeal mucosa and host immunity in general. ${ }^{51}$ Both may affect the risk of invasion of a colonising organism, and the former may also result in an altered risk of acquisition through changes in the expression of adhesion molecules on the epithelial cell surface and the cytokine milieu, which may favour bacterial invasion. ${ }^{52}$ 
Structural changes in the respiratory tract that have been attributed to tobacco smoke include peribronchiolar inflammation and fibrosis, increased mucosal permeability, impairment of mucociliary clearance, changes in pathogen adherence and disruption of the respiratory epithelium, ${ }^{52} 53$ which are thought to predispose individuals to the development of respiratory tract infections. While the nasopharyngeal flora of smokers may contain fewer normal commensal bacteria and more potential pathogens than seen among non-smokers, ${ }^{54}$ tobacco smoke can also affect cell-mediated and humoral immune responses in humans and animals. ${ }^{53}$ Smoking can also be a fetal determinant for IMD, as shown in a Danish case-control study finding associations between low birth weight $(<2500 \mathrm{~g})$ and risk for IMD (OR 1.5, $95 \%$ CI 1.0 to 2.3), and between maternal smoking and IMD. ${ }^{55} 56$ The elevated risk for IMD persisted throughout early childhood. This adds to previous studies showing that maternal smoking during pregnancy and environmental tobacco smoke exposure during pregnancy are associated with low birth weight. ${ }^{57}$ The proportion of children born in Norway with low birth weight $(<2500 \mathrm{~g})$ was, however, relatively stable in the period 1975-2008 (5.26.4\%) (http://www.norgeshelsa.no).

\section{Implications for practice and conclusions}

We have demonstrated a statistically significant, independent association between incidence of IMD in children under 5 years of age and the prevalence of smoking at the population level in Norway, supporting results of case-control studies, as well as animal data and in vitro biological studies. This is, therefore, highly likely to represent the causation rather than just association. The observed decline in IMD incidence over the past $30-40$ years in a number of high-income countries worldwide may, therefore, be at least partly explained by a reduction in smoking. These data suggest that smoking in the parental age group has the biggest influence on disease in young children, consistent with known contact patterns of these children and transmission dynamics of $N$. meningitidis. To verify whether the association between IMD and smoking in Norway is reproducible in other settings, similar studies should be performed in regions with a high rate of daily smokers. For this to be enabled, it is vital that countries collect high-quality data not only on IMD and smoking, but also on possible confounding variables of this interaction to allow future prospective analysis to be undertaken to confirm our findings. Efforts to reduce smoking should be considered as an essential component of public health measures to reduce meningococcal disease, in addition to other specific interventions such as routine immunisation.

\section{Author affiliations}

${ }^{1}$ Oxford Vaccine Group, Department of Paediatrics, University of Oxford, and the NIHR Oxford Biomedical Research Centre, Oxford, UK

${ }^{2}$ Norwegian Institute of Public Health, Oslo, Norway
${ }^{3}$ Centre for Statistics in Medicine, University of Oxford, Oxford, UK ${ }^{4}$ Department of Infectious Disease Epidemiology, Statens Serum Institut, Copenhagen S, Denmark

${ }^{5}$ University of Örebro, Örebro, Sweden

${ }^{6}$ ThinkTank Tobaksfakta, Stockholm, Sweden

${ }^{7}$ Department of Medical Microbiology, The Netherlands Reference Laboratory for Bacterial Meningitis, Academic Center, Amsterdam, The Netherlands

Acknowledgements The authors would like to thank the following people and organisations for their assistance in obtaining the data and contributing scientific advice: Jon Michael Gran, Bjørn Iversen, Öistein Løvoll and Dominique A. Caugant (Norwegian Institute of Public Health); Arne Andersen (Statistics Norway); Rita Lindbak and Arnfinn Helleve (Norwegian Directorate of Health); Annika Linde and Sandra Rubinova (Swedish Institute for Communicable Disease Control); Mathias Jansson (National Institute of Public Health, Sweden); Anne Nærvig-Petersen (Statistics Denmark); Annette Hartvig Christiansen (Statens Serum Institut); Jan Gravestein (NIVEL); Dr Tarquinia Zeegers (STIVORO).

Contributors GN, MS, 00, L-MY and AJP were responsible for study design. GN, MS, AJP, KM, MH, PO, MH and AvdE participated in data collection. 00 and L-MY undertook the statistical analyses. GN and MS wrote the manuscript. All authors revised the manuscript, and reviewed and approved the final version. AJP is the guarantor for the study. All authors had full access to all the data (including statistical reports and tables) in the study and can take responsibility for the integrity of the data and the accuracy of the data analysis.

Funding This study was supported by the Oxford Partnership Comprehensive Biomedical Research Centre with funding from the Department of Health's NIHR Biomedical Research Centres funding scheme. MS was funded by Action Medical Research through a Research Training Fellowship (RTF1263) AJP is a Jenner Institute Investigator and James Martin Senior Fellow. The funders had no role in study design, data collection and analysis, decision to publish, or preparation of the manuscript.

Disclaimer The views expressed in this publication are those of the authors and not necessarily those of the Department of Health.

Competing interests All authors have completed the ICMJE uniform disclosure form at www.icmje.org/coi_disclosure.pdf and declare: no support from any organisation for the submitted work; no financial relationships with any organisations that might have an interest in the submitted work in the previous three years; no other relationships or activities that could appear to have influenced the submitted work.

Provenance and peer review Not commissioned; externally peer reviewed.

Data sharing statement The study was based on aggregated, anonymised data that were publicly available and collected as part of national infectious disease statistics. Data used in this study were either available in the public domain or used by approval from the respective data owners in the study countries. Statistical code and dataset are available from the corresponding author at gunnstein.norheim@fhi.no.

Open Access This is an Open Access article distributed in accordance with the Creative Commons Attribution Non Commercial (CC BY-NC 3.0) license, which permits others to distribute, remix, adapt, build upon this work noncommercially, and license their derivative works on different terms, provided the original work is properly cited and the use is non-commercial. See: http:// creativecommons.org/licenses/by-nc/3.0/

\section{REFERENCES}

1. World Health Organization. Control of epidemic meningococcal disease. WHO practical guidelines. 2nd edn. Geneva, Switzerland: World Health Organization, 1998.

2. Booy R, Habibi P, Nadel S, et al. Reduction in case fatality rate from meningococcal disease associated with improved healthcare delivery. Arch Dis Child 2001;85:386-90.

3. Thorburn K, Baines $\mathrm{P}$, Thomson A, et al. Mortality in severe meningococcal disease. Arch Dis Child 2001;85:382-5.

4. Offit PA, Peter $\mathrm{G}$. The meningococcal vaccine-public policy and individual choices. N Engl J Med 2003;349:2353-6. 
5. Ramsay M, Fox A. EU-IBIS Network. Invasive Neisseria meningitidis in Europe 2006. London: Health Protection Agency, 2007.

6. Cohn AC, MacNeil JR, Harrison LH, et al. Changes in Neisseria meningitidis disease epidemiology in the United States, 1998-2007: implications for prevention of meningococcal disease. Clin Infect Dis 2010;50:184-91.

7. Cartwright KAV, Stuart JM, Jones DM, et al. The Stonehouse survey: nasopharyngeal carriage of meningococci and Neisseria lactamica. Epidemiol Infect 1987;99:591-601.

8. Caugant DA, Høiby EA, Magnus $P$, et al. Asymptomatic carriage of Neisseria meningitidis in a randomly sampled population. J Clin Microbiol 1994;32:323-30.

9. Cheever FS. The meningococci. In: Dubos RJ, Hirsch JG, eds. Bacterial and mycotic infections of man. 4th edn. Philadelphia, PA: J. B. Lipincott Co., 1965:440-50.

10. Tzeng YL, Stephens DS. Epidemiology and pathogenesis of Neisseria meningitidis. Microbes Infect 2000;2:687-700.

11. Blackwell CC, Weir DM, James VS, et al. Secretor status, smoking and carriage of Neisseria meningitidis. Epidemiol Infect 1990;104:203-9.

12. Blackwell CC, Tzanakaki G, Kremastinou J, et al. Factors affecting carriage of Neisseria meningitidis among Greek military recruits. Epidemiol Infect 1992;108:441-8.

13. Thomas JC, Bendana NS, Waterman SH, et al. Risk factors for carriage of meningococcus in the Los Angeles County men's jail system. Am J Epidemiol 1991;133:286-95.

14. Neal KR, Nguyen-Van-Tam JS, Jeffrey $\mathrm{N}$, et al. Changing carriage rate of Neisseria meningitidis among university students during the first week of term: cross sectional study. BMJ 2000;320:846-9.

15. Riordan T, Cartwright K, Andrews N, et al. Acquisition and carriage of meningococci in marine commando recruits. Epidemiol Infect 1998;121:495-505.

16. Simmons G, Martin D, Stewart J, et al. Carriage of Neisseria meningitidis among household contacts of patients with meningococcal disease in New Zealand. Eur J Clin Microbiol Infect Dis 2001;20:237-42.

17. MacLennan J, Kafatos G, Neal K, et al. Social behavior and meningococcal carriage in British teenagers. Emerg Infect Dis 2006;12:950-7.

18. Coen PG, Tully J, Stuart JM, et al. Is it exposure to cigarette smoke or to smokers which increases the risk of meningococcal disease in teenagers? Int J Epidemiol 2006;35:330-6.

19. McCall BJ, Neill AS, Young MM. Risk factors for invasive meningococcal disease in southern Queensland, 2000-2001. Intern Med J 2004;34:464-8.

20. Kriz P, Bobak M, Kriz B. Parental smoking, socioeconomic factors, and risk of invasive meningococcal disease in children: a population based case-control study. Arch Dis Child 2000;83:117-21.

21. Baker M, McNicholas A, Garrett N, et al. Household crowding a major risk factor for epidemic meningococcal disease in Auckland children. Pediatr Infect Dis J 2000;19:983-90.

22. Fischer $M$, Hedberg $K$, Cardosi $P$, et al. Tobacco smoke as a risk facto for meningococcal disease. Pediatr Infect Dis J 1997;16:979-83.

23. Tappero JW, Reporter R, Wenger JD, et al. Meningococcal disease in Los Angeles County, California, and among men in the county jails. N Engl J Med 1996;335:833-40.

24. World Health Organization. WHO report on the global tobacco epidemic. Warnings about the dangers of tobacco. Geneva, Switzerland: World Health Organization. 2011.

25. Haneberg B, Tönjum T, Rødahl K, et al. Factors preceding the onse of meningococcal disease, with special emphasis on passive smoking, symptoms of ill health. NIPH Ann 1983;6:169-73.

26. Stanwell-Smith RE, Stuart JM, Hughes AO, et al. Smoking, the environment and meningococcal disease: a case control study. Epidemiol Infect 1994;112:315-28.

27. Imrey PB, Jackson LA, Ludwinski PH, et al. Outbreak of serogroup $\mathrm{C}$ meningococcal disease associated with campus bar patronage. Am J Epidemiol 1996;143:624-30.

28. Bruce MG, Rosenstein NE, Capparella JM, et al. Risk factors for meningococcal disease in college students. JAMA 2001;286:688-93.

29. Tully J, Viner RM, Coen PG, et al. Risk and protective factors for meningococcal disease in adolescents: matched cohort study. BMJ 2006;332:445-50.

30. Bjune G, Høiby EA, Grønnesby JK, et al. Effect of outer membrane vesicle vaccine against group $B$ meningococcal disease in Norway. Lancet 1991;338:1093-6.

31. Mossong J, Hens $\mathrm{N}$, Jit $\mathrm{M}$, et al. Social contacts and mixing patterns relevant to the spread of infectious diseases. PLoS Med 2008:5:e74.
32. Forey $\mathrm{B}$, Hamling J, Lee $\mathrm{P}$, et al. International smoking statistics. A collection of historical data from 30 economically developed countries. Oxford: Oxford University Press, 2002.

33. Gran JM, Iversen B, Hungnes $\mathrm{O}$, et al. Estimating influenza-related excess mortality and reproduction numbers for seasonal influenza in Norway, 1975-2004. Epidemiol Infect 2010;138:1559-68.

34. Spiegelman D, Hertzmark E, Wand HC. Point and interval estimates of partial population attributable risks in cohort studies: examples and software. Cancer Causes Control 2007;18:571-9.

35. Royston P. Multiple imputation of missing values: update of ice. Stata J 2005;5:527-36.

36. Rubin D. Multiple imputation for nonresponse in surveys. New York: Wiley, 1987.

37. Murray RL, Britton J, Leonardi-Bee J. Second hand smoke exposure and the risk of invasive meningococcal disease in children: systematic review and meta-analysis. BMC Public Health 2012;12:1062.

38. Gorber SC, Schofield-Hurwitz S, Hardt J, et al. The accuracy of self-reported smoking: a systematic review of the relationship between self-reported and cotinine-assessed smoking status. Nicotine Tob Res 2009;11:12-24.

39. du Prel JB, Puppe W, Grondahl B, et al. Are meteorological parameters associated with acute respiratory tract infections? Clin Infect Dis 2009;49:861-8.

40. Jensen ES, Lundbye-Christensen S, Samuelsson S, et al. A 20-yea ecological study of the temporal association between influenza and meningococcal disease. Eur J Epidemiol 2004;19:181-7.

41. Paul M, Held L, Toschke AM. Multivariate modelling of infectious disease surveillance data. Stat Med 2008;27:6250-67.

42. Jansen AG, Sanders EA, Van Der Ende A, et al. Invasive pneumococcal and meningococcal disease: association with influenza virus and respiratory syncytial virus activity? Epidemiol Infect 2008;136:1448-54.

43. Sheppard L. Insights on bias and information in group-level studies. Biostatistics 2003;4:265-78.

44. Moore PS. Meningococcal meningitis in sub-Saharan Africa: a model for the epidemic process. Clin Infect Dis 1992;14:515-25.

45. Watkins ER, Maiden MCJ. Persistence of hyperinvasive meningococcal strain types during global spread as recorded in the PubMLST database. PLoS ONE 2012;7:e45349.

46. Lee CC, Middaugh NA, Howie SRC, et al. Association of secondhand smoke exposure with pediatric invasive bacteria disease and bacterial carriage: a systematic review and meta-analysis. PLoS Med 2010;7:e1000374.

47. Edmunds WJ, Kafatos G, Wallinga J, et al. Mixing patterns and the spread of close-contact infectious diseases. Emerg Themes Epidemiol 2006;3:10.

48. Zagheni E, Billari FC, Manfredi $\mathrm{P}$, et al. Using time-use data to parameterize models for the spread of close-contact infectious diseases. Am J Epidemiol 2008;168:1082-90.

49. Raghunathan PL, Jones JD, Tiendrebeogo SR, et al. Predictors of immunity after a major serogroup W-135 meningococca disease epidemic, Burkina Faso, 2002. J Infect Dis 2006;193:607-16.

50. Stuart JM, Robinson PM, Cartwright KAV, et al. Effect of smoking on meningococcal carriage. Lancet 1989;2:723-5.

51. Sopori M. Effects of cigarette smoke on the immune system. Nat Rev Immunol 2002;2:372-7.

52. Dye JA, Adler KB. Effects of cigarette smoke on epithelial cells of the respiratory tract. Thorax 1994;49:825-34.

53. Marcy TW, Merrill WW. Cigarette smoking and respiratory tract infection. Clin Chest Med 1987;8:381-91.

54. Brook I. Effects of exposure to smoking on the microbial flora of children and their parents. Int $J$ Pediatr Otorhinolaryngol 2010;74:447-50.

55. Sorensen HT, Labouriau R, Jensen ES, et al. Fetal growth, maternal prenatal smoking, and risk of invasive meningococcal disease: a nationwide case-control study. Int J Epidemiol 2004; 33:816-20.

56. Goldacre MJ, Wotton CJ, Maisonneuve JJ. Maternal and perinatal factors associated with subsequent meningococcal, Haemophilus or enteroviral meningitis in children: database study. Epidemiol Infect 2013:1-8.

57. Leonardi-Bee J, Smyth A, Britton J, et al. Environmental tobacco smoke and fetal health: systematic review and meta-analysis. Arch Dis Child Fetal Neonatal Ed 2008;93:F351-61. 